\title{
Masseteric Vein
}

National Cancer Institute

\section{Source}

National Cancer Institute. Masseteric Vein. NCI Thesaurus. Code C53051.

The veins that drain blood from the masseter muscle into the pterygoid venous plexus. 